\title{
Development Prospect of China's New Consumer Economy in the New Situation-Concurrently Discussing the Impact of COVID-19
}

\author{
Jieying Chen ${ }^{1}$, Hongchun $\mathrm{Li}^{2}$ \\ ${ }^{1}$ School of Economics, Jinan University, Guangzhou, China \\ ${ }^{2}$ Guangdong Energy Group Finance Co., Ltd., Guangzhou, China \\ Email:1hc1943@163.com,jnulhc@outlook.com
}

How to cite this paper: Chen, J. Y., \& Li, H. C. (2020). Development Prospect of China's New Consumer Economy in the New Situation-Concurrently Discussing the Impact of COVID-19. Open Journal of Business and Management, 8, 1201-1215. https://doi.org/10.4236/ojbm.2020.83077

Received: April 27, 2020

Accepted: May 17, 2020

Published: May 20, 2020

Copyright ( 2020 by author(s) and Scientific Research Publishing Inc. This work is licensed under the Creative Commons Attribution International License (CC BY 4.0). http://creativecommons.org/licenses/by/4.0/

\begin{abstract}
As the world's most potential consumer market, China's new consumer economy, which consists of new demand, new supply, new fields and new technologies, is full of vitality. In recent years, influenced by the economic and social development, the constantly updated consumption concept and with the rapid development of technology in the Internet field, the new consumption economy such as health care, education, entertainment and tourism is changing with each passing day. In addition, under the influence of COVID-19, "Contactless delivery" continues to be popular in online shopping, takeaway, and online consultation. Combined with the impact of the epidemic, this paper makes an in-depth analysis of the development of China's new consumer economy, as well as the opportunities and challenges.
\end{abstract}

\section{Keywords}

New Consumer Economy, COVID-19, Online Shopping, Big Data

\section{Introduction}

At the beginning of 2020, the epidemic of COVID-19 raged, which was at the time of the traditional Chinese New Year. The epidemic had a great impact on the economy and society. Traditional industries including retail, catering, tourism and transportation were hit hard. On February 15, the Ministry of Transport expects passenger traffic to drop by $45 \%$ year-on-year in 2020 , especially during the second half of the Spring Festival. The number of passengers has shrunk 
dramatically, and some areas of passenger traffic have even returned to zero.

Affected by the epidemic, home isolation has become the focus of the epidemic prevention and control work. The demand for online shopping and takeout, fresh home delivery, online courses, remote office and game video has soared. According to news published by Sina Finance website ${ }^{1}$, the number of online orders for Hema Fresh has surged by $220 \%$ compared with the same period last year. What's more, office software server requests such as WeChat Enterprise and Ding Talk rose more than 10 times over the same period.

During the "SARS" raging in 2003, e-commerce began to emerge in China; many e-commerce giants in China have developed since then. Not only did Alibaba's business stagnate during the epidemic, but the number of members and information posted on the website increased substantially. Specifically, the average daily number of new members exceeds 3000 , and the daily average number of new business information is about 10,000 , up about $50 \%$ and $300 \%$ respectively over the same period. In addition, JD also has a similar development path during the "SARS" period (Li et al., 2020). Now, coincided with the opportunity of China's economic transformation to high-quality development, which industries will stand out, can the new consumer economy become the new kinetic energy and new opportunities for China's future economy?

\section{Connotation and Characteristics of the New Consumer Economy}

Since the reform and opening up, China's economic and social development has continued, and its consumption level has been continuously improved, with obvious characteristics of the times. Li Rongqing (2015) summarized several important stages of China's social consumption: The stage of material acquisition (1978-2000), the main feature of this stage is the people's pursuit of material enrichment and satisfaction; The quality acquisition phase (2000-2015), after the material is satisfied, consumers are more inclined to pursue the diversity of consumption and the high quality of consumption; The experience acquisition stage (from 2015 to the present), with the advancement of Internet and communication technology, the proportion of service consumption has increased in this stage, mainly experience-based consumption and social consumption. Consumers are more active in the consumption process, focusing on the acquisition of consumption sense.

Shi Mingming et al. (2019) pointed out that the most fundamental reason for the consumption change is the continuous improvement of productivity and the continuous increase of income level, which in turn leads to the continuous improvement of residents' consumption level and level. Furthermore, Xue Junmin and Jin Mei (2019) pointed out that the consumption level of residents and the level of economic development are mutually reinforcing. In addition, the development of the level of opening to the outside world, the level of knowledge and ${ }^{1}$ http://finance.sina.com.cn/stock/relnews/us/2020-02-13/doc-iimxyqvz2469893.shtml. 
the level of science and technology also have a huge impact.

In the new era, great changes have been taken place in China's economic and social foundation. Unbalanced and inadequate development has become a major contradiction that restricts people's pursuit of a better life. In this context, consumption methods, consumption levels, consumption content and consumption structure must be comprehensively improved and upgraded (Mao \& Ye, 2017). Hu Yangyang and Zhang Tongquan (2018) believe that with reference to Maslow's hierarchy of needs, there is a similar evolutionary process of consumption behavior from traditional material consumption to spiritual and cultural consumption. On the whole, the essence of the new consumer economy is the stage change of residents' consumer demand, especially with the innovation of network technology and the enrichment of social media. The new consumer economy is constantly changing the business model, and its concepts and definitions are constantly expanding.

\section{1) Definition of the new consumer economy}

In a broad sense, the new consumption economics is a business model that covers the consumption of goods, consumption experience satisfaction, and behavioral data analysis. It is a brand-new economic model that is different from traditional business consumption.

The most obvious feature of the new consumer economy is that consumers are the center, relying on the Internet and other information technologies, and the level of interaction between consumers and producers is enhanced. The purpose is to pursue high-quality consumer quality. Specific forms include social sharing, live experience, remote collaboration, personalized customization.

In a narrow sense, the new consumer economy is based on Internet communications, mobile apps, and social networking platforms. Consumer preferences are concentrated in new areas such as health care, tourism education, entertainment consumption, and pet raising. The usual forms of consumption include: customization, crowd funding and sharing. In addition, in terms of traditional consumption fields such as clothing, food, housing and transportation, it also shows more personalized, informatized and shared characteristics.

\section{2) Characteristics of the new consumer economy}

Ran Yan (2019) believes that with the increasing convenience of transportation and logistics, the continuous development and progress of information and communication technology, the new consumer economy features mainly include the following four aspects: "online + offline" interactive consumption, social consumption, and IP (Intellectual Property) consumption and sharing economy (Secondhand market). Based on the existing literature, compared with the traditional consumption economic model, the main characteristics of the new consumption economy also include personalization, intelligence and interactivity.

Personalise. Personalized consumption effectively meets the consumer psychology of the new era and satisfies consumers' sense of acquisition to a great extent, which is a distinctive feature of the new consumer economy. I have no 
one, I have gifted is the core demand of new consumers. After the basic consumption needs are effectively met, consumers are more inclined to personalized consumption in higher fields, including education, tourism etc. In the field of learning, more and more training institutions set up small classes or even private classes. Correspondingly, consumers are also more inclined to choose to study or participate in training for their hobbies or occupations. Personalized value-added services are provided by all kinds of industries including daily necessities, food and beverage. Standardized industrial products such as automobiles and mobile phones even provide considerate services like accessory selection, color selection, and text engraving. In particular, different consumers may open the same webpage or APP (application) with completely different content according to personalized and intelligent recommendations based on the portraits of consumer behavior and consumption priorities through big data.

Intelligent. "Internet of Everything (IOE)" is not only the current development trend of science and technology, but also an important reflection of the new consumption economic model. With the increasing advancement of network communication technology, especially the popularity of smart phones, it provides a solid technical guarantee for the new consumer economy. On the one hand, emerging business models rely on the rapid rise of Internet technologies, such as bike sharing, face-to-face payment, live streaming, online education, AR visits etc. The rapid development of information technology and intelligent hardware makes the consumption channels unblocked, the convenience of consumption methods and the intelligent of consumption scenarios. On the other hand, the traditional consumption scenarios have also been subverted, and the level of intelligence is increasing day by day. Takeaway food ordering is common, and fresh food delivery is gradually sought after. Tracing every process of food safety through block chain technology has become the consumers' ultimate pursuit. AR fitting room, online makeup has been popular for a long time. Air conditioners, refrigerators and televisions with intelligent functions such as WIFI, voice interaction and cameras have been accepted by the public. Driverless cars have been tested in a number of cities. Intelligent network of the car brings a more fantastic experience while traveling.

Interactivity. Compared with the traditional consumer economy, the continuous enhancement of consumer interaction makes the new consumer economy more dynamic. In traditional consumption scenarios, the roles of buyers and sellers are relatively determined, and the trading venues and modes are relatively fixed. Under the new consumer economy model, buyers and sellers maintain close interactions. Different kinds of personnel including web celebrity live broadcast with goods and agricultural craftsmen communicate with customers directly through online market. Meanwhile, lots of manufacturers consumers maintain interaction on time with customers in order to modify and improve the product according to personal preferences in time. In this way, consumers will fully experience the sense of gain. At the same time, consumer-to-consumer interaction 
has also been strengthened, especially in the context of rapid development of social networks. Price-cutting, review forwarding, shared leasing and second-hand market transactions have become consumer-consumer typical representative of interaction. By using big data, joint marketing and data sharing between sellers and sellers are also important features of the new consumer economy.

\section{Development Status of New Consumer Economy}

\section{1) Service consumption continues to expand}

With the continuous development of the economy and society, the residents' material consumption level has been greatly enriched, and the proportion of new consumption such as health consumption, sports consumption and knowledge consumption continues to rise. Judging from the performance of the Engel coefficient, since the reform and opening up, the Engel coefficient of urban and rural residents in China has decreased significantly. In 2019, the Engel coefficient of national residents was $28.2 \%$, a decrease of 0.2 percentage points from the previous year. According to the relevant standards for the division of the Engel coefficient by the United Nations, China is already among the rich countries.

According to the data from National Bureau of Statistics, the total per capita service consumption expenditure was 9886 yuan in 2019, an increase of $12.6 \%$ over the previous year, accounting for $45.9 \%$ of the per capita consumption expenditure of residents, which has become an important part of household consumption expenditure. As shown in Table 1, since 2000, the per capita consumption expenditure of residents of medical, communications and education and other new consumption per capita expenditure has maintained a high year-on-year growth rate. Specifically, the average annual growth rate of per capita consumer expenditure in the fields of transportation and communication, medical and education is: $14.37 \%, 11.71 \%, 10.29 \%$, which is significantly higher than the growth rate of $8.27 \%$ for clothing and $7.95 \%$ for food (Notes: Due to the substantial increase in per capita housing expenditure of residents in 2014, the average value does not include the 2014 data).

As an important part of the new consumer economy, tourism not only maintains rapid growth, but also innovates in tourism models. In March, China Tourism Research Institute recently released the "Basic Situation of the National Tourism Market in 2019", the number of domestic tourists in China was 6.006 billion in 2019, an increase of $8.4 \%$ over the same period of the previous year. The total number of inbound and outbound tourists was 300 million, an increase of $3.1 \%$ year-on-year. Night tours, tourism learning, and in-depth experience tourism have become the highlights of the tourism industry.

\section{2) Intelligent consumption boom emerges}

In the new consumption economy, intelligent consumption not only means the full use of high-tech means in all aspects of consumption, but also includes consumers' increased consumption of information products and information 
Table 1. The growth trend of per capita consumption of urban residents in China from 2000 to 2019.

\begin{tabular}{|c|c|c|c|c|c|c|c|}
\hline $\begin{array}{c}\text { Years/ } \\
\text { Index } \\
(\%)\end{array}$ & $\begin{array}{c}\text { Total } \\
\text { Consumption }\end{array}$ & $\begin{array}{l}\text { Transportation } \\
\text { and } \\
\text { Communication }\end{array}$ & $\begin{array}{l}\text { Medical } \\
\text { and } \\
\text { Health }\end{array}$ & $\begin{array}{c}\text { Education } \\
\text { and } \\
\text { Entertainment }\end{array}$ & Households & Clothes & Food \\
\hline 2000 & 8.28 & 27.20 & 29.50 & 10.72 & 10.24 & 3.75 & 1.36 \\
\hline 2001 & 6.22 & 15.70 & 7.93 & 9.90 & 9.48 & 6.63 & 2.84 \\
\hline 2002 & 13.58 & 36.98 & 25.29 & 30.77 & 13.94 & 10.72 & 12.80 \\
\hline 2003 & 7.98 & 15.19 & 10.67 & 3.56 & 12.02 & 7.93 & 6.39 \\
\hline 2004 & 10.31 & 16.99 & 10.96 & 10.53 & 4.88 & 7.69 & 12.11 \\
\hline 2005 & 10.59 & 18.15 & 13.77 & 6.26 & 10.24 & 16.56 & 7.56 \\
\hline 2006 & 9.49 & 15.09 & 3.28 & 9.62 & 11.81 & 12.65 & 6.78 \\
\hline 2007 & 14.96 & 18.33 & 12.66 & 10.48 & 8.64 & 15.55 & 16.58 \\
\hline 2008 & 12.46 & 4.40 & 12.46 & 2.19 & 16.61 & 11.89 & 17.41 \\
\hline 2009 & 9.09 & 18.73 & 8.93 & 8.43 & 7.29 & 10.15 & 5.13 \\
\hline 2010 & 9.84 & 17.90 & 1.79 & 10.52 & 8.40 & 12.47 & 7.28 \\
\hline 2011 & 12.54 & 8.37 & 11.15 & 13.77 & 5.47 & 15.95 & 14.60 \\
\hline 2012 & 9.98 & 14.22 & 9.77 & 9.82 & 5.64 & 8.88 & 9.71 \\
\hline 2013 & 8.09 & 11.46 & 5.13 & 12.81 & 17.58 & 4.31 & 4.49 \\
\hline 2014 & 10.79 & -3.64 & 16.75 & -6.61 & 157.26 & -14.45 & -4.94 \\
\hline 2015 & 7.13 & 9.79 & 10.55 & 11.23 & 5.27 & 4.54 & 6.00 \\
\hline 2016 & 7.88 & 9.62 & 13.00 & 10.71 & 8.21 & 2.23 & 6.32 \\
\hline 2017 & 5.92 & 4.66 & 8.95 & 7.92 & 8.80 & 1.09 & 3.53 \\
\hline 2018 & 6.82 & 4.55 & 15.14 & 4.46 & 12.42 & 2.84 & 3.40 \\
\hline 2019 & 7.47 & 5.70 & 11.58 & 11.90 & 8.39 & 1.33 & 6.82 \\
\hline $\begin{array}{l}\text { Average } \\
\text { Value }\end{array}$ & 9.40 & 14.37 & 11.71 & 10.29 & 9.75 & 8.27 & 7.95 \\
\hline
\end{tabular}

services. First of all, and delivery of drones are flourishing, enabling consumers to enjoy high-tech consumption anytime and anywhere, which also promoting online consumption carnival recognized by the whole people, such as the "double 11 " shopping festival. Consumers are able to enjoy the immersive shopping experience with high-speed Internet and advanced AR technology while staying at home because of the COVID-19. The perfect cold chain, as well as the delivery time calculated by the minute, make fresh home become an effective alternative to the offline market. Even the government departments launched "online office" services, all of which bring people a lot of convenience.

Secondly, information services, information products and other emerging consumer fields are gradually gaining popularity. Consumers' awareness of knowledge payment and copyright protection has gradually become clearer, and their willingness to pay for virtual products has been further strengthened, in- 
cluding music video website members, genuine software and game props, which have become the "The Three Magic Weapons" under the new consumer economic model. Many special measures taken to effectively control the epidemic have profoundly changed consumer preferences. According to the report "Online Entertainment Insight under the Epidemic during the Spring Festival 2020" released by Mob Research Institute, more consumers have increased the use of online entertainment and services, and the number of iQiyi, Mango TV and Tencent video members have increased by $1079 \%, 708 \%$ and $319 \%$ respectively. And the online medical consultations such as Ping an Health Cloud and Lilac Garden have increased by more than 10 times.

3) Environmentally friendly and shared consumption patterns are popular

Environmental protection consumption has gradually become a new consumption model that conforms to economic development. Similarly, the sharing economy has gradually been accepted by consumers. And the traditional concept of consumption is different is that in the new economic model of consumption, consumers pay more attention to whether consumer behavior environmentally friendly, but also more concerned about the sustainability of the resource. Energy-saving home appliances, water-saving appliances, and green food are not only gradually favored by consumers, but also become the main propaganda content of businesses.

As early as 2017, Apple announced that it is committed to creating new products such as iPhone, iPad and Mac to achieve $100 \%$ recyclable materials or renewable materials, while trying to improve the recycling process of old equipment. Other internationally renowned fast-selling companies such as Uniqlo and Levi's have also proposed similar plans. On December 27, 2019, the JD Big Data Research Institute released the "2019 Green Consumption Trend Development Report" that pointed out that the types of green consumer products on the JD platform have exceeded 100 million, and their sales growth rate is much higher than other products in the market.

In addition, the concept of sharing is also popular. The continued prosperity of the leasing and second-hand trading market has become an important manifestation of resource recycling and green consumption, effectively promoting the transfer and reuse of commodity values. In recent years, shared products such as shared bicycles, shared cars, and shared charging treasures have sprung up. While meeting consumer needs, they have also effectively achieved the goal of continuous development and reuse of idle resources. Under the catalysis of the sharing economy, many second-hand trading platforms have risen rapidly. The domestic mainstream second-hand trading platforms include XianYu, ZhuanZhuan, and GUAZI in the second-hand automobile field. The number of users of the multiple trading platforms listed above and the number of daily active users have increased rapidly, not only the number of registered users exceeds 100 million, but also the GMV (Gross Merchandise Volume) reaches 100 
billion. Taking XianYuas an example, in 2018, more than 1 million users posted more than 2 million personal idle items on XianYu. The cumulative number of baby items released by XianYu users has exceeded 1.4 billion.

\section{Opportunities for New Consumer Economic Models}

\section{1) New ideas promote new consumption}

According to the model of new consumption economics, the new consumption economy is affected by three new consumption parameters: new consumption objects, new lifestyles, and new consumption concepts (Ran, 2019). With the continuous development of China's economy and the increasing degree of opening to the outside world, the consumption concepts of mainstream consumer groups have undergone tremendous changes. On the one hand, with the rapid economic development and continuous improvement of living standards, residents are liberated from the high Engel coefficient and turned to high-quality consumption; at the same time, the continuous improvement of legal guarantees and the increasing awareness of rights protection have increased the demand for enjoyable consumption by laborers, promote the consumption of tourism and training to a large extent. On the other hand, the consumption ideas of developed countries such as Europe, America, Japan and South Korea are constantly influx, which has a great influence on the consumption behavior and ideas of our people.

Among them, "Otaku Culture" and credit consumption are the most typical. The "Otaku Economy" derived from the "Otaku Culture" has driven new wave of consumption such as online shopping and takeaway, as well as consumption of online virtual products such as animation and games. Credit consumption gives consumers more choices, and the payment in installments further promote upgrade of consumption level. At the same time, different lifestyles have driven different models of the new consumer economy. For example, choose the "Single Economy" spawned by bachelorism (Kan, 2019); the "Pet Economy" spawned by pets.

\section{2) New technologies drive new consumption}

The fast-growing Internet is the technological carrier of the new consumer economy. Technological innovations such as 5G, block chain technology and drone equipment, especially the development of big data technology, have brought a leap in precision marketing and supply chain management, thus further Promote the vigorous development of the new consumer economy (Hong, 2018). First, the high Internet penetration rate has created the foundation for a new consumer economy. According to the China Internet Network Information Center (CNNIC) released the 44th "Statistical Report on Internet Development in China" in Beijing: As of June 2019, the number of Internet users in China reached 854 million, of which the number of mobile Internet users reached 847 million, and Internet users use mobile phones. The proportion of Internet access reached $99.1 \%$, and the Internet penetration rate reached $61.2 \%$. Secondly, major 
innovations in communication technologies such as $5 \mathrm{G}$ have become the engines of the new consumer economy. Real-time live streamings and real-time interactions have further accelerated the innovation of the entertainment industry. AR and VR have further enriched the consumer experience. Especially during the epidemic, online house purchases, live streaming and car sales have suddenly emerged.

Finally, with the rapid development of logistics and fresh cold chain technology, while the traditional logistics efficiency is increasing day by day, the fresh food storage and transportation technology has also developed by leaps and bounds. JD and Tmall supermarkets have basically reached the next day, and some regions can even receive the goods on the same day. Hema Fresh and MISS FRESH delivery in the city can be accurate to the minute, to ensure that the seafood products received by the user are still fresh. SF Express, as the leader of cross-region fresh fruit distribution in the industry, adopts one-stop cold chain and segmented cold chain according to the fresh food category. One-stop cold chain refers to the fresh food that is put in the warehouse. Control measures, with the help of temperature control boxes, ice bags, insulation bags and other temperature control equipment to achieve the entire cold chain. The segmented cold chain is a half-way cold chain that directly supplies raw materials from the origin, such as cherries and lychees, by adding temperature control materials such as ice packs to the package when it is shipped from the origin (Shao \& Lu, 2018).

\section{3) New crisis stimulates new consumption}

Economic and social development, technical bottlenecks, and the promulgation of major policies may all become the industry's black swans, and even devastating blows to specific industries, but often after the crisis, new industries and new business models will rise rapidly. The outbreak of the SARS epidemic in 2003 promoted the birth and development of online shopping represented by Taobao, making it the current largest e-commerce platform in China and a typical case for studying the new consumer economy. The financial crisis of 2008 greatly changed people's consumption concepts and also promoted the emergence and development of a new consumer economy in disguise. In addition, the Melamine incident in the dairy industry, the Plasticizer incident in the liquor industry, and the "Air Hostess Murder" in the travel field have undoubtedly devastated the industry. But often after the crisis, through industry rectification, commercial mode improvements and technological innovations will renew the industry's new brilliance, making consumers more comfortable and safer to consume.

The sudden COVID-19 epidemic occurred during the traditional Chinese New Year holidays, which caused a devastating blow to the traditional catering, aviation, film and tourism industries. Thousands of flights were canceled, all movie theaters in the country were had to closed, and almost all tourist attractions are closed. However, the epidemic also opened the ceiling of other indus- 
tries. Industries such as fresh e-commerce, online education, and games are welcoming major benefits. According to the "2020 China Mobile Internet" War Epidemic Special Report released by Quest Mobile, the overall daily live users of fresh e-commerce companies have increased from about 8 million during the Spring Festival and exceeded 10 million during the Spring Festival, and once again exceeded 12 million after the holiday, an increase of up to $60 \%$.

The cash flow of the well-known mobile game "Glory of the King" on New Year's Eve reached 2 billion yuan, a record high in human history. According to the relevant data released by Alipay, more than 600 million people used Alipay to check the epidemic situation, online consultation, grocery shopping and medicine delivery, health declaration, and the same itinerary query and other 48 services during the outbreak. It can be seen that the new consumer economy in the crisis can not only meet consumer demand, but also reallocate resources, but also an important manifestation of social self-repair.

\section{4) New policies guarantee new consumption}

In order to adapt to the vigorous development of the new consumer economy, many countries, industry associations and enterprises have formulated relevant regulations and policies to effectively protect the rights and interests of consumers and better safeguard the healthy and stable development of the new consumer economy. As early as 2018, the government promulgated the "E-commerce Law of the People's Republic of China". The law raises the barriers to entry. It requires e-commerce platforms to bear joint and several liability for counterfeit goods. In 2019, the National Development and Reform Commission, the Ministry of Commerce and other departments issued relevant regulations and policies to further provide legal protection and policy support for the development of a new consumer economy. At the same time, Beijing, Guangzhou, Chengdu and many other cities have also introduced measures to promote the new consumption economy, actively using cash technology and policy measures to vigorously promote the development of the new consumption economy.

In particular, more and more regulatory agencies and enterprises themselves are actively formulating relevant policies to effectively improve the problems and defects arising from the development of the new consumer economy. In recent years, including the Central Cyber Office, the China Consumers Association, the China Internet Association etc., have formulated relevant regulations and measures, focusing on combating counterfeiting, piracy and fraud in new consumer areas such as online shopping, online payment and game props. In addition, head companies such as Taobao, JD and WeChat have formulated strict platform specifications, and through identity authentication, face recognition and big data analysis, have minimized the phenomenon of brushing orders, the prevalence of fakes and fraudulent transactions happened.

\section{Challenges Facing the New Consumer Economy}

1) The level of infrastructure intelligence needs to be improved 
The new consumer economy has strong intellectual characteristics. Whether it is shared cars, unmanned supermarkets or fresh home delivery, not only needs advanced business models, but also needs perfect infrastructure to support it.

In particular, it also puts forward new requirements for urban infrastructure planning. The birth of the sharing economy requires more shared areas in the city; the development of the "Otaku Culture" requires more intelligent facilities in the community; personalized customization requires more free exhibition space in the business center.

Obviously, the infrastructure under the traditional economy cannot meet the hardware needs of the continuous development of the new consumer economy. First, there is the issue of network communication support. The dependence of the new consumer economy on the Internet is obvious. Nationwide, high-speed and developed communication networks have not yet been fully established, and some remote areas still cannot achieve smooth network signal coverage, which greatly limits the development potential of the new consumer economy in some areas. Secondly, there is the issue of logistics and distribution. The fresh food storage and transportation network has not yet been fully established. The traditional logistics system has not yet reached the level of large-scale commercial use of fresh agricultural products such as fish and shrimp. Whether it is the distribution of fresh produce in urban areas or the agricultural and sideline products produced in rural areas, it faces the problem of timeliness of distribution.

In cities, the emergence of intelligent express cabinets has effectively improved the logistics "last mile" problem, but the "last mile" conditions for the distribution of fresh products such as fish, shrimp, fruits and vegetables need to be improved. In rural areas, most rural areas have inconvenient transportation, and logistics cannot establish transfer stations or delivery points, which restricts the development of a new rural consumer economy. According to CFLP (Cold Chain Logistics Committee of CFLP) data, the cold chain rate of agricultural products in China is only $45 \%$, while the cold chain rate of agricultural products in developed countries has reached $95 \%$. Finally, there is the issue of shared regional planning. Due to the shared characteristics of the new consumer economy, the placement of many shared commodities has become a major issue in current urban planning. Taking shared bicycles as an example, the huge number of shared bicycles has a sharp increase in the demand for public bicycle parking spaces. Most cities cannot meet the problem of bicycle parking in the short term. Superimposed chaotic management results in bicycle parking in disorder and even blocks roads. These all give cities roads management and traffic safety bring greater pressure. Similarly, the parking problem of shared cars also severely limits the further development of shared cars.

2) Vicious competition is not conducive to the development of the new consumer economy

Although the new consumer economy is developed from the traditional economy, it has the characteristics of rapid market change, low barriers to entry, low 
plagiarism cost, high homogeneity, fierce market competition, and obvious Matthew effect. Therefore, there is not only vicious competition among enterprises, but even illegal acts such as price collusion. Taking e-commerce as an example, Internet applications are no longer a blue ocean, and the penetration rate of online shopping users is nearing its peak. According to CNNIC (China Internet Network Information Center) data, as of June 2019, the size of Internet and online shopping users was 850 million and 640 million, respectively, and the growth rate was only $1.6 \%$ and $4.7 \%$ from the end of 2018 , which means that the industry has entered the era of stock competition.

In the e-commerce field, the price war between Suning and JD in 2012 opened consumers' eyes and opened the door to price competition among e-commerce companies. Continued price competition will inevitably bring about problems such as declining service levels and sub-optimal quality, and is not conducive to the long-term stable development of the industry. The competition of e-commerce platforms also harms suppliers, and the rise of new e-commerce such as PDD has further aggravated the vicious competition of "Two Choose One" in the e-commerce industry. Companies including Tmall and JD require suppliers to only products that can be launched on this platform, such as Meituan and ELE, have not only mandated restaurants to "Two Choose One", but even there have been fights on different platforms to rob business.

In the era of big data, customers mean the market. Not only in the field of e-commerce, but also in the field of entertainment consumption such as music, games and livestreaming, there are also malicious competitions. Some livestreaming platforms have spent a lot of money to sign big-name stars in the fields of games and music for traffic, resulting in frequent malicious digging in the industry, leading companies to only focus on traffic, but have no time to improve technology and improve customer service. In addition, various video websites and music platforms have forced the locking of popular traffic stars and their works, resulting in some consumers needing to download multiple videos and music software at the same time, which undoubtedly increases the cost of consumption and reduces the consumption experience, which is not conducive to the long-term development of the entertainment and consumer industry.

\section{3) Counterfeiting and infringement damage consumer rights}

The biggest difference between the new consumption economic model and the traditional economy is that its market changes rapidly, the forms of transactions are diverse, the subjects of transactions are diversified, and the characteristics of product virtualization are obvious. While enjoying intelligence and convenience, consumers also face consumption risks such as counterfeit and shoddy products and online fraud.

First, the interests of consumers are damaged. In order to solve the bottleneck problem of corporate profit growth, large enterprises use mergers and acquisitions to gain access to the market, and use the entry barriers to scale effects under the new consumer economy. In addition, large platforms can use the infor- 
mation of a large number of consumers to further block new competition (Chen, 2018). Furthermore, in a price market with asymmetric information, consumer rights and interests have been damaged to varying degrees. Various e-commerce, ticketing, and carpooling platforms have exposed price discrimination incidents, using the platform's big data to monitor the consumption behavior and payment habits of different individuals, and charge different individuals different fees. Although companies can achieve profitability in the short term, in the long run, consumer loyalty to corporate brands has declined, corporate reputation has declined, and even legal sanctions that companies will face.

Secondly, consumers' personal privacy is violated. In the era of big data, consumers' personal privacy information has become an extremely important capital in the market, and has also become a resource that major enterprises are competing for. On the one hand, in the initial stage, major companies used low-price, gifts, discounts and other marketing methods to create a variety of business models such as multi-person group purchases, social pooling, and lottery draws to obtain a large amount of consumer personal information; On the other hand, consumers are not very aware of their own privacy information protection, leaking personal privacy information without knowing it. In addition, various types of APPs excessively collect consumer personal information and compulsorily read irrelevant other information, leading to the leakage and sale of personal privacy information.

4) Regulatory regulations lag behind the development of the new consumer economy

Under the new consumption economic model, the consumption scenarios are diverse, and the business model innovation is rapid, which makes it difficult for the traditional regulatory system to effectively adapt to the development trend of the new consumer economy. Chaotic phenomena such as post-regulation, over-regulation, lack of regulation, and misalignment often occur, which seriously restricts the new the development of the consumer economy.

First of all, traditional geographical supervision has caused inconvenience for consumers to protect their rights. All along, China usually adopts the principle of territorial management for the main body of the market economy. However, under the new consumer economy, the scale of business of the company spreads over most of the country, which is not consistent with the place of registration of the enterprise. When a consumer in a non-registered place has a dispute with an enterprise, the consumer must spend additional rights protection costs to defend the rights. In most cases, the cost of consumer rights protection is too high and the difficulty is too great, which may easily lead to the lack of a proper way of defending rights, thereby suppressing consumer demand for new consumption.

Second, bull management can easily lead to chaos in management. In China, different industries are under the supervision of different departments, and each industry's supervisory responsibilities fall under different departments and industry associations. In the era of the new consumer economy, enterprises under 
Internet blessing are engaged in cross-industry operations. Usually, the basic business of an enterprise involves multiple industries such as e-commerce, financial management, catering, entertainment, medical and health. The industry supervision model is difficult to solve the above problems. In the long run, the lack of industry supervision, major regulatory authorities blame each other, and repeated supervision has seriously affected the normal business activities of Internet companies and increased the cost of rent-seeking.

\section{Conclusion}

This article takes the latest developments in industries such as online medical care, fresh food distribution and gaming entertainment as the starting point during the new coronary epidemic. It also focuses on the development of the new consumer economy under the current situation and further analyzes the opportunities and challenges it faces. In the short term, the impact of the epidemic on the economy is mainly concentrated in industries such as catering, tourism and transportation. If the epidemic further deteriorates or lasts longer, it will have a greater impact on the entire consumption and investment, further increasing the downward pressure on the economy. In the long run, China's economic foundation will continue to increase in resilience and its fundamentals will become more stable. Short-term shocks will not change the long-term trend of our economy.

For objective and subjective reasons, this article has the following deficiencies. Firstly, the time factor: The short research time has caused the lack of research data to some extent. In the past four months, the COVID-19 has spread globally. Short-term economic activity data are difficult to reflect the impact of COVID-19 on the Chinese economy, especially the long-term impact. Secondly, the space factor: The COVID-19 epidemic spreads faster than most people expected. This led to the author's perspective being limited to the domestic field, which lead to the failure to take into account the worldwide impact of COVID-19. Undoubtedly, in the context of globalization, analyzing and reflecting on the impact of the COVID-19 from a global perspective is of great benefit in preventing future global public health crisis. On the other hand, in the context of globalization, it is more practical to think about the impact of COVID-19 on China's domestic economy.

China's economic development has entered a new era. The people's longing for a better life is the fundamental driving force for the development of China's new consumer economy. First of all, government functional departments should take the initiative to stay close to the market, pay attention to market dynamics, promptly and appropriately promulgate relevant regulations and management methods, and actively lead and regulate the development of the new consumer economy; Secondly, enterprises should continue to increase scientific and technological innovation, enhance the ability of industrial coordinated development, strictly abide by laws and regulations and industry guidelines, abide by business 
ethics, and provide a solid material and technical foundation for the development of the new consumer economy; Finally, under the wave of the Internet, consumers need to enhance their identification ability, use tools such as the Internet in a civilized and reasonable manner, and enjoy the rights while actively practicing the consumer's main obligations.

\section{Conflicts of Interest}

The authors declare no conflicts of interest regarding the publication of this paper.

\section{References}

Chen, C. (2018). The Characteristics of Network Economics of Group Buying and The Way of Enterprise Competition. Knowledge Economy, 20, 157-162.

Hong, Y. (2018). The Way to Realize the Commercial Value of Retail Enterprises under the Background of Big Data. Business Economics Research, 1, 33-35.

Hu, Y. Y., \& Zhang, T. Q. (2018). Research on the Differences and Influencing Factors of Cultural Consumption of Urban and Rural Residents in China-Based on Maslow's Demand Hierarchy Theory of Distribution Lag Model. Business Economics Research, 13, 210-215.

Kan, L. L. (2019). “Single Economy” Spawns New Consumption. New Sankei, 12, 40-43.

Li, C., Zhu, X., \& Sun, O. (2020). Comparison between Huatai Securities and The Impact of SARS: Changes and Unchanged After the New Crown Epidemic. Nanjing: Huatai Securities.

Li, R. Q. (2015). Construction of Experience Marketing Path for Department Store Format under New Consumption Environment. Business Times, 2, 59-62.

Mao, Z. G., \& Ye, X. (2017). The New Era and New Consumption Continue to Meet the People 'S Growing Need for a Better Life-The Experience of Studying and Implementing the Consumption Statement of the 19th National Congress of the Party. Finance and Economics, 11, 15-20.

Ran, Y. (2019). Exploring the New Consumption Model in the Context of the Era of Big Data. Chinese Business Review, 11, 60-62.

Shao, T. W., \& Lu, X. M. (2018). Consumer Experience Setting of Fresh E-Commerce Based on Consumer Sovereignty. China Management Science, 8, 12-15.

Shi, M. M., Jiang, Z., \& Zhou, X. Y. (2019). Consumption Upgrade or Consumption Downgrade. China Industrial Economy, 7, 120-123.

Xue, J. M., \& Jin, M. (2019). Residents' Consumption Upgrade and High-Quality Economic Development: An Empirical Study Based on Chinese Inter-Provincial Panel Data. Commercial Economic Research, 22, 77-79. 